\title{
Effect of Silane Coupling Agent on Flexural Strength and Hardness of Wheat Straw Polystyrene Composites
}

\author{
R.S.N Sahai ${ }^{*}$, R.A. Pardeshi ${ }^{2}$ and D. Biswas $^{1}$ \\ ${ }^{1}$ Department of General Engineering, Institute of Chemical Technology, Mumbai, 400019, India \\ ${ }^{2}$ Department of Polymer and Plastic Engineering, Institute of Petrochemical Engineering, Lonere, Raigad, India
}

\begin{abstract}
In the present research work, the effect of silane treatment along with alkali treatment on flexural strength, flexural modulus, and hardness investigated. Wheat straw as a filler was added (5\%, 10\%, $15 \%$ and $20 \%$ ) to polystyrene matrix to prepare wheat straw polystyrene composite. The wheat straw fibre was first treated with $20 \% \mathrm{NaOH}$ and $1 \%$ silane coupling agent to prepare wheat straw polystyrene composite. The compounding process was carried out in twin-screw extruder and samples were prepared by the compression moulding process. There was an increase in flexural modulus (214\%), flexural strength (44\%), and hardness (28\%) of composite with the addition of alkali and silane treated wheat straw fibre.
\end{abstract}

Keywords: Polystyrene; wheat straw; silane coupling agent; alkali treatment

\section{INTRODUCTION}

Natural fibre polymer composites are getting increasingly attention in the polymer composite research area because of distinctive properties such as low density, high specific properties, and eco-friendly as mentioned (Nabi Saheb \& Jog, 1999; Pickering, Efendy \& Le, 2016; Atmakuri et. al., 2020; Gholampour \& Ozbakkaloglu, 2020). The incorporation of natural fibre has resulted in improved mechanical properties of polymer composites (Mishra \& Naik, 2005).

The effect of different types of natural fibre along with its various factors such as fibre dimensions and source of natural fibre on performance of natural fibre polymer composites has been reported (Singha and Rana, 2012; Mohammed et al., 2015). The incorporation of rice husk fibre as filler resulted in the higher tensile modulus of the composite (Park et al., 2016). The addition of jute fibre and agave fibre as filler in the polymer matrix provided polymer composite with superior mechanical properties was highlighted by (Sinha \& Panigrahi, 2009; Singha \& Rana, 2013; Kumar \& Srivastava, 2017). The addition of wheat straw as filler in natural fibre polymer composites resulted in superior mechanical properties of polymer composites (Bisanda, 2000; Panthapulakkal, Zereshkian \& Sain, 2006; Kellersztein \& Dotan, 2016). Incorporation of wheat straw shows better results compared to other fillers such as wood flour and others for wheat straw reinforced HDPE polymer composites (Panthapulakkal \& Sain, 2007). There is an increase in Young's modulus with increase in filler loading of plantain peel reinforced polystyrene composites (Adeniyi et al., 2020).

Poor compatibility between the natural fibre and polymer matrix is a great challenge (Westman et al., 2010). Various chemical treatments of fibres are carried out in order to improve the compatibility of natural fibre with polymer matrix (Panthapulakkal, Zereshkian \& Sain, 2006) to obtain the better performance of natural fibre polymer composites (Li, Tabil \& Panigrahi, 2007). Silanes are prominently used as coupling agent in natural fibre composite. Because hydrolyzed silane solutions have an enhance affinity for the hydroxyl sites of natural fibre, it improves compatibility between natural fibre and polymer matrix (Abdelmouleh et. al., 2002; Sahai \& Pardeshi, 2019). Silane has been used for various polymer matrix such as polyethylene, polystyrene, epoxy, PVC etc. (Valadez-Gonzalez et. al., 1999; Rong et. al., 
2001; Xie et al., 2010). The application of the silane coupling agent increased the tribological properties of polymer composites (Goriparthi, Suman \& Mohan Rao, 2012; Nishitani, Kajiyama \& Yamanaka, 2017; Milosevic, Valášek \& Ruggiero, 2020). Higher compatibility between polymer matrix and natural fibre with the application of silane as the coupling agent has been reported (Yoon et al., 2020).

Alkali treatment of natural fibres results in removal of hemicellulose and lignin resulting in increased surface area for better mechanical interlocking and enhancing possible reaction sites (Li, Tabil \& Panigrahi, 2007; Sgriccia, Hawley \& Misra, 2008; Sahai \& Pardeshi, 2019; Alhijazi et al., 2020). Alkali treatment improves the degradation temperature of wheat straw fibre (Mittal \& Sinha, 2017). The degradation temperature of wheat straw was increased to $264^{\circ} \mathrm{C}$ on alkali treatment which is higher than processing temperature of polystyrene (Sahai \& Pardeshi, 2019). The alkali treatment of fibres resulted in better mechanical properties of polymer composites (Ray et. al., 2001; Nam et. al., 2011; Oushabi et al., 2017). The application of silane coupling agent along with alkali treatment resulted in polymer composites with superior mechanical properties were reported in (Srisuwan, Jarukumjorn \& Suppakarn, 2018; Sahai \& Pardeshi, 2019).

The application of maleic anhydride resulted in better performance of natural fibre polymer composites was reported in previous studies (Mishra \& Naik, 2005; Mengeloglu \& Karakus, 2008; Yoon et al., 2020).

This study aims to develop a wheat straw polystyrene composite with superior mechanical properties and environment friendly.

\section{MATERIALS AND METHOD}

\section{A. Raw Materials}

In this research work, polystyrene being used as polymer matrix material. Polystyrene (GPPS Grade) (SC 206) with an MFI $12 \mathrm{gm} / 10$ minutes was obtained from Supreme Petrochem Limited, Mumbai, India. Wheat straw fibres were procured from the farmland of Ujjain, Madhya Pradesh. Silane was obtained from Avra Synthesis Pvt. Ltd.

The wheat straw fibre was chopped (4-6 mm) and washed and dried properly. The fibres were initially dried to remove excess water and impurities and soaked in $20 \%(\mathrm{w} / \mathrm{v})$ sodium hydroxide solution (liquor ratio 20:1, for 30 minutes). After the treatment process, these were neutralized with a dilute acetic acid solution, and further it is washed thoroughly with distilled water and finally dried.

About 1\% silane solution, i.e. 3-aminopropyltriethoxy was prepared using acetone. The $\mathrm{pH}$ of the solution was adjusted to 4.0 with acetic-acid and was stirred for 5 minutes. The wheat straw fibres were placed in the solution for a duration of 1 hour. The fibres were later removed from the solution and were dried in the oven maintaining a constant temperature of $100^{\circ} \mathrm{C}$ for a duration of 12 hours.

Compounding of wheat straw polystyrene composite was carried out in twin-screw extruders. (RPM 80-100). Processing temperature of Zone 1,2,3,4 and dies were $180^{\circ} \mathrm{C}$, $200^{\circ} \mathrm{C}, 220^{\circ} \mathrm{C}, 230^{\circ} \mathrm{C}$ and $250^{\circ} \mathrm{C}$. Pelletizing was carried out after compounding in a twin-screw extruder. Sheets were prepared using compression moulding at a temperature of $220^{\circ} \mathrm{C}$. Samples were prepared using ASTM D79o for flexural test and ASTM D785.

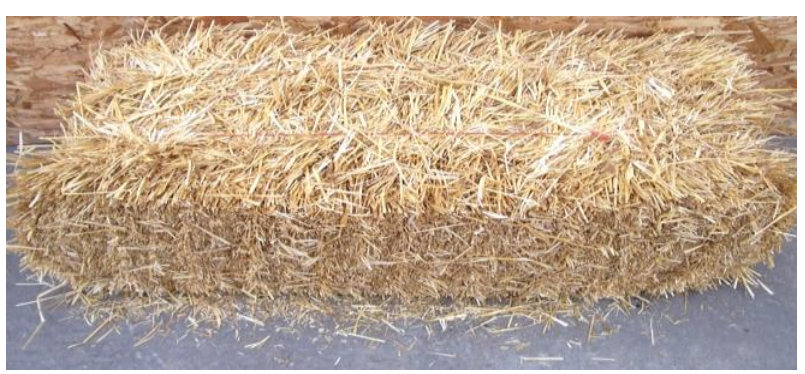

Figure 1. Wheat straw fibre

\section{RESULT AND DISCUSSION}

\section{A. Flexural Strength}

Figure 3 represents the change in flexural strength of wheat straw polystyrene composites with variation in wheat straw fibre loading. From the figure we can observe that as we increase the wheat straw fibre loading, there is a substantial increase in the flexural strength of the material. Flexural strength is obtained maximum at $5 \%$ fibre loading which decreases with an increase in fibre loading up to $20 \%$. However, the value of flexural strength even at $20 \%$ fibre loading is higher than the flexural strength of polystyrene without filler. There is an improved interaction of polymer matrix with fibre because of increased surface roughness of 
fibre on alkali treatment and higher possible mechanical interlocking and chemical bonding (Bisanda, 2000).

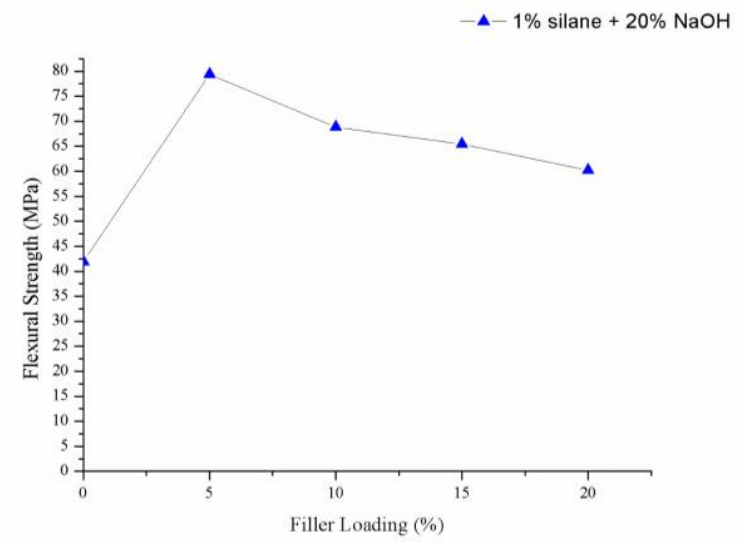

Figure 3. Flexural strength of polystyrene wheat straw composites

The silane coupling agent is more effective in enhancing the mechanical properties of wheat straw polystyrene composites because of better fibre-matrix compatibility (Sood \& Dwivedi, 2018; Sahai \& Pardeshi, 2019). The decrease in flexural strength can be attributed to the possible rise of fibre defects due to an increase in fibre concentration which acts as a source of stress concentration (Sawpan, Pickering \& Fernyhough, 2012). However, the influence of better interfacial adhesion between alkali and silane treated fibre with polymer matrix overcomes this decline, resulting in a higher value of flexural strength compared to virgin polystyrene even at $20 \%$ of fiber loading.

\section{B. Flexural Modulus}

Figure 4 represents the change in flexural modulus of wheat straw polystyrene composites with variation in wheat straw fibre loading. It is observed that there is an increase in flexural modulus with an increase in wheat straw fibre loading. There is a significant rise in flexural modulus for $5 \%$ fibre loading which then decreases with an increase in further fibre loading up to $20 \%$. However, the value of flexural modulus even at $\mathbf{2 0} \%$ fiber loading is much higher than the flexural modulus of polystyrene without filler. There is an improved interaction of polymer matrix with fibre because of increased surface roughness of fiber on alkali treatment and higher possible mechanical interlocking and chemical bonding.
The silane coupling agent is more effective in enhancing the mechanical properties of wheat straw polystyrene composites again due to better fibre-matrix compatibility as a result of alkali treatment. The rise in flexural modulus can be again attributed to higher interfacial bonding between alkali and silane treated wheat straw fibre and polystyrene composite (Webo, Masu \& Maringa, 2018).

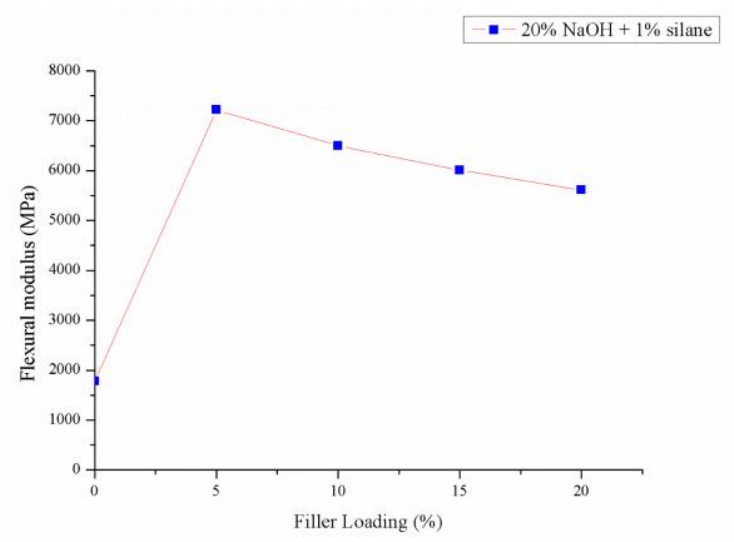

Figure 4. Flexural modulus of polystyrene wheat straw composites

\section{Hardness}

Figure 5 represents the change in Rockwell hardness of wheat straw polystyrene composites with variation in wheat straw fibre loading. There is an increase in Rockwell hardness for a direct increase in wheat straw fibre loading. Rockwell hardness is maximum at $5 \%$ fibre loading which decreases for an increase in further fibre loading up to $20 \%$. For an increase in fibre loading from $5 \%$ to $10 \%$, the rate of decrease is minimum as compared to a higher rate of decrease for fibre loading for $10 \%$ to $15 \%$ and $20 \%$. However, the value of Rockwell hardness even at 20\% fiber loading is higher than Rockwell's hardness of polystyrene without filler. The rise in hardness can be attributed to improving interfacial bonding between the wheat straw fibre and polystyrene matrix (Webo, Masu \& Maringa, 2018). 


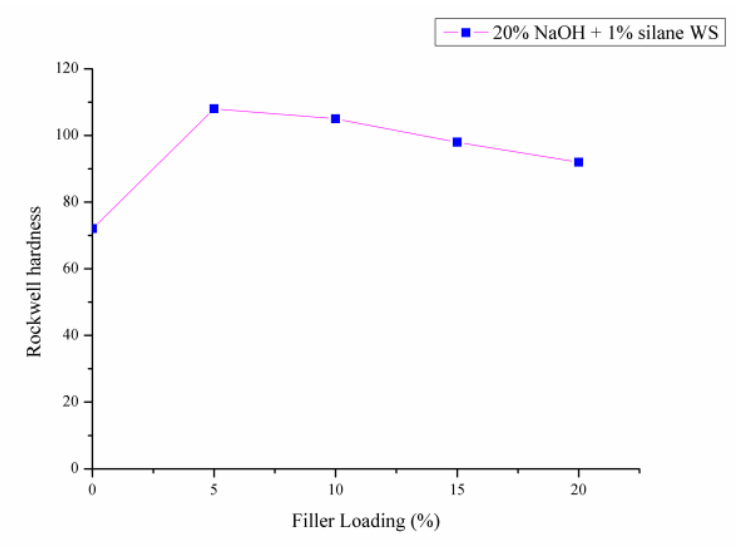

Figure 5. Hardness of polystyrene wheat straw composites

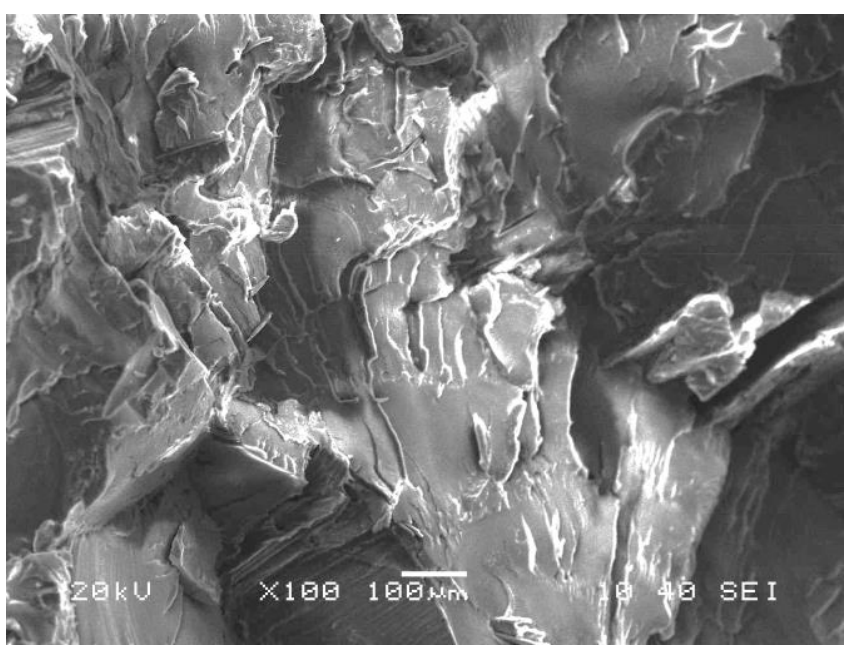

Figure 6. SEM of alkali and silane treated wheat straw-filled polystyrene composite

Figure 6 shows a scanning electron microscopic (SEM) image of alkali and silane treated wheat straw reinforced polystyrene composites. Alkali treatment along with the silane coupling agent is very effective in improving interfacial adhesion between fiber and polymer matrix because of higher surface roughness resulting in superior flexural strength.

\section{CONCLUSION}

There is an increase in flexural strength, flexural modulus, and hardness of wheat straw polystyrene composites with the addition of filler loading. The flexural strength, flexural modulus, and hardness of wheat straw polystyrene composites are maximum at $5 \%$ fiber loading.

\section{ACKNOWLEDGEMENT}

The authors would like to acknowledge the Institute of Chemical Technology, Mumbai, India for carrying out the research activities.

\section{DECLARATION OF CONFLICTING INTEREST}

The author(s) declared no potential conflicts of interest with respect to the research, authorship, and/or publication of this article.

\section{FUNDING}

The author(s) received no financial support for the research, authorship, and/or publication of this article.

doi: $10.3390 /$ su12187683.

Atmakuri, A, Palevicius, A, Vilkauskas, A \& Janusas, G 2020, 'Review of hybrid fiber based composites with nano particles-material properties and applications', Polymers, vol. 12, no. 9, pp. 2088. doi: 10.3390/polym12092088.

Bisanda, ETN 2000, 'Effect of alkali treatment on the adhesion characteristics of sisal fibres', Applied Composite Materials, vol. 7, no. 5-6, pp. 331-339. doi: 10.1023/A:1026586023129.

Gholampour, A \& Ozbakkaloglu, T 2020, 'A review of natural fiber composites: properties, modification and processing techniques, characterization, applications', Journal of 
Materials Science, vol. 55, no. 3, pp. 829-892. doi: 10.1007/s10853-019-03990-y.

Goriparthi, BK, Suman, KNS \& Mohan Rao, N 2012, 'Effect of fiber surface treatments on mechanical and abrasive wear performance of polylactide/jute composites', Composites Part A: Applied Science and Manufacturing, vol. 43, no. 10, pp. 1800-1808. doi: 10.1016/j.compositesa.2012.05.007.

Kellersztein, I \& Dotan, A 2016, 'Chemical surface modification of wheat straw fibers for polypropylene reinforcement', Polymer Composites, vol. 37, no. 7, pp. 2133-2141. doi: 10.1002/pc.23392.

Kumar, A \& Srivastava, A 2017, 'Preparation and mechanical properties of jute fiber reinforced epoxy composites', Industrial Engineering \& Management, vol. 6, no. 4. doi: 10.4172/2169-0316.1000234.

Li, X, Tabil, LG \& Panigrahi, S 2007, 'Chemical treatments of natural fiber for use in natural fiber-reinforced composites: a review', Journal of Polymers and the Environment, vol. 15, no. 1, pp. 25-33. doi: 10.1007/s10924-006-0042-3.

Mengeloglu, F \& Karakus, K 2008, 'Thermal degradation, mechanical properties and morphology of wheat straw flour filled recycled thermoplastic composites', Sensors, vol. 8, no. 1, pp. 500-519. doi: 10.3390/s8010500.

Milosevic, M, Valášek, P \& Ruggiero, A 2020, 'Tribology of natural fibers composite materials: an overview', Lubricants, vol. 8, no. 4, pp. 42. doi: 10.3390/lubricants8040042.

Mishra, S \& Naik, JB 2005, 'Effect of treatment of maleic anhydride on mechanical properties of natural fiber: polystyrene composites', Polymer - Plastics Technology and Engineering, vol. 44, no. 4, pp. 663-675. doi: 10.1081/PTE200057814 .

Mittal, V \& Sinha, S 2017, 'Effect of alkali treatment on the thermal properties of wheat straw fiber reinforced epoxy composites', Journal of Composite Materials, vol. 51, no. 3 , pp. 323-331. doi: 10.1177/o021998316646168.

Mohammed, L, Ansari, MN, Pua, G, Jawaid, M \& Islam, MS 2015, 'A review on natural fiber reinforced polymer composite and its applications', International Journal of Polymer Science, 2015. doi: 10.1155/2015/243947.

Nabi Saheb, D \& Jog, JP 1999, 'Natural fiber polymer composites: a review', Advances in Polymer Technology, vol. 18, no. 4, pp. 351-363. doi: 10.1002/(SICI)10982329(199924)18:4<351::AID-ADV6>3.0.CO;2-X.

Nam, TH, Ogihara, S, Huy Tung, N \& Kobayashi, S 2011, 'Effect of alkali treatment on interfacial and mechanical properties of coir fiber reinforced poly(butylene succinate) biodegradable composites', Composites Part B: Engineering, vol. 42, no. 6, pp. 1648-1656. doi: 10.1016/j.compositesb.2011.04.001.

Nishitani, Y, Kajiyama, T \& Yamanaka, T 2017, 'Effect of silane coupling agent on tribological properties of hemp fiber-reinforced plant-derived polyamide 1010 biomass composites', Materials, vol. 10, no. 9, pp. 1040. doi: 10.3390/ma10091040.

Oushabi, A, Sair, S, Hassani, FO, Abboud, Y, Tanane, O \& El Bouari, A 2017, 'The effect of alkali treatment on mechanical, morphological and thermal properties of date palm fibers (DPFs): study of the interface of DPFPolyurethane composite', South African Journal of Chemical Engineering, vol. 23, pp. 116-123. doi: 10.1016/j.sajce.2017.04.005.

Panthapulakkal, S \& Sain, M 2007, 'Agro-residue reinforced high-density polyethylene composites: fiber characterization and analysis of composite properties', Composites Part A: Applied Science and Manufacturing, vol. 38, no. 6, pp. 1445-1454. doi: 10.1016/j.compositesa.2007.01.015.

Panthapulakkal, S, Zereshkian, A \& Sain, M 2006, 'Preparation and characterization of wheat straw fibers for reinforcing application in injection molded thermoplastic composites', Bioresource Technology, vol. 97, no. 2, pp. 265-272. doi: 10.1016/j.biortech.2005.02.043.

Park, IK, Hau, NC, Kim, YJ, Yun, JH, Kim, SH, Suhr, J, Lee, YK \& Nam, JD 2016, 'A study of PP/natural fiber composites using thermoplastic lignin-polyester and nanoclay', Polymer (Korea), vol. 40, no. 5, pp. 744-750. doi: 10.7317/pk.2016.40.5.744.

Pickering, KL, Efendy, MGA \& Le, TM 2016, 'A review of recent developments in natural fibre composites and their mechanical performance', Composites Part A: Applied Science and Manufacturing, vol. 83, pp. 98-112. doi: 10.1016/j.compositesa.2015.08.038.

Ray, D, Sarkar, BK, Rana, AK \& Bose, NR 2001, 'Effect of alkali treated jute fibres on composite properties', Bulletin of Materials Science, vol. 24, no. 2, pp. 129-135. doi: 10.1007/BFo2710089.

Rong, MZ, Zhang, MQ, Liu, Y, Yang, GC \& Zeng, HM 2001, 'The effect of fiber treatment on the mechanical properties of unidirectional sisal-reinforced epoxy composites', Composites Science and Technology, vol. 61, no. 10, pp. 1437-1447. doi: 10.1016/So266-3538(01)oo046-X.

Sahai, RSN \& Pardeshi, RA 2019, 'Comparative study of effect of different coupling agent on mechanical properties and 
water absorption on wheat straw-reinforced polystyrene composites', Journal of Thermoplastic Composite Materials, pp. 089270571984397. doi: 10.1177/0892705719843975.

Sawpan, MA, Pickering, KL \& Fernyhough, A 2012, 'Flexural properties of hemp fibre reinforced polylactide and unsaturated polyester composites', Composites Part A: Applied Science and Manufacturing, vol. 43, no. 3, pp. 519526. doi: 10.1016/j.compositesa.2011.11.021.

Sgriccia, N, Hawley, MC \& Misra, M 2008, 'Characterization of natural fiber surfaces and natural fiber composites', Composites Part A: Applied Science and Manufacturing, vol. 39, no. 10, pp. 1632-1637. doi: 10.1016/j.compositesa.2008.07.007.

Singha, AS \& Rana, RK 2012, 'Natural fiber reinforced polystyrene composites: effect of fiber loading, fiber dimensions and surface modification on mechanical properties', Materials and Design, vol. 41, pp. 289-297. doi: 10.1016/j.matdes.2012.05.001.

Singha, AS \& Rana, RK 2013, 'Preparation and properties of agave fiber-reinforced polystyrene composites', Journal of Thermoplastic Composite Materials, vol. 26, no. 4, pp. 513526. doi: 10.1177/0892705711425848.

Sinha, E \& Panigrahi, S 2009, 'Effect of plasma treatment on structure, wettability of jute fiber and flexural strength of its composite', Journal of Composite Materials, vol. 43, no. 17, pp. 1791-1802. doi: 10.1177/o021998309338078.

Sood, M \& Dwivedi, G 2018, 'Effect of fiber treatment on flexural properties of natural fiber reinforced composites: a review', Egyptian Journal of Petroleum, vol. 27, no. 4, pp. 775-783. doi: 10.1016/j.ejpe.2017.11.005.

Srisuwan, L, Jarukumjorn, K \& Suppakarn, N 2018, 'Effect of silane treatment methods on physical properties of rice husk flour/natural rubber composites', Advances in Materials Science and Engineering, 2018, pp. 1-14. doi: 10.1155/2018/4583974.

Valadez-Gonzalez, A, Cervantes-Uc, JM, Olayo, R \& HerreraFranco, PJ 1999, 'Chemical modification of henequén fibers with an organosilane coupling agent', Composites Part B: Engineering, vol. 30, no. 3, pp. 321-331. doi: 10.1016/S1359-8368(98)ooo55-9.

Webo, W, Masu, L \& Maringa, M 2018, 'The impact toughness and hardness of treated and untreated sisal fibre-epoxy resin composites', Advances in Materials Science and Engineering, 2018, pp. 1-10. doi: 10.1155/2018/8234106.

Westman, MP, Fifield, LS, Simmons, KL, Laddha, S \& Kafentzis, TA 2010, Natural fiber composites: a review. richland, WA,United States. doi: 10.2172/989448.
Xie, Y, Hill, CAS, Xiao, Z \& Militz, H 2010, 'Silane coupling agents used for natural fiber/polymer composites: a review', Composites Part A: Applied Science and Manufacturing, vol. 41, no. $7, \quad$ pp. 806-819. doi: 10.1016/j.compositesa.2010.03.005.

Yoon, HJ, Bomin G, Jonghyuk, L, Jeongeun, P, Jonghwi, Jo, J, Kyungho, J \& Jeongjae, W 2020, 'Thermal and mechanical properties of polypropylene/cellulose nanofiber composites', Polymer Korea, vol. 44, no. 3, pp. 255-263. doi: 10.7317/pk.2020.44.3.255. 